\title{
How the Adaptation Got its Start
}

\author{
Anastasia Thanukos
}

Published online: 15 October 2009

(C) The Author(s) 2009. This article is published with open access at Springerlink.com

Keywords Adaptation · Exaptation · Teaching

Most of us are understandably amazed by the marvelous adaptations of plants, animals, and even fungi and microbes: acacias that dutifully supply nectar and grow thorny homes for the ants that protect them from herbivores (Janzen 1966), anglerfish that tempt their prey into striking range with a lure inhabited by glowing bacteria (Leisman et al. 1980), parasitic fungi that drive their doomed insect hosts up blades of grass to better distribute their spores, and bacteria that can easily survive in boiling water thanks to their heat-resistant proteins (Stetter 1999). Such features are undeniably impressive-but narrowly focusing on their current function ignores what is often the equally compelling story of their evolutionary history.

In an article in this issue (Becoming Modern Homo sapiens), Ian Tattersall (2009) addresses a concept that gets at the evolutionary history of currently useful traits: exaptation, a feature that performs a function but that was not produced by natural (or sexual) selection for its current use. Tattersall's discussion focuses on the human capacity for symbolic thinking, but the idea applies broadly throughout the living world. Here, we will dig into the concept of exaptation, find out why it is important, and see how we can use the concept in understanding the evolutionary history of traits.

\section{A. Thanukos $(\bowtie)$}

University of California Museum of Paleontology,

1101 Valley Life Sciences Building,

Berkeley, CA 94720-4780, USA

e-mail: thanukos@berkeley.edu

URL: http://evolution.berkeley.edu

\section{What is Exaptation?}

We are all familiar with the idea of adaptation - a feature produced by selection for its current use. For example, male barn swallows have tail feathers shaped into long streamers. These are unwieldy from an aerodynamic standpoint but are effective at seducing the opposite sex. The length of these feathers seems to be an adaptation shaped by sexual selection to attract mates (Møller et al. 1998). When the feathers first began to evolve extra-long lengths (beyond what was helpful for maneuverability), the advantage probably had to do with attracting mates - and that extra length comes in handy for the same reasons today.

Exaptations, on the other hand, did not evolve in the context of their current use. They may have originally evolved to serve a different function or may have evolved as a byproduct of the evolution of a different feature. For example, we tend to think of bird feathers as beautiful adaptations for flight because they do such a great job of enabling flight today, but the evolutionary history of feathers tells a different story. Recently, paleontologists have unearthed many fossils of feathered, but flightless, dinosaurs (Norrell and $\mathrm{Xu}$ 2005). This suggests that feathers evolved long before birds did-in their dinosaur ancestors (Fig. 1). The very first feathers may have been nothing more than a downy fuzz that helped dinosaurs regulate their body temperatures (Ewart 1921) or served some other, non-flight-related function. Later, these feathers evolved into more specialized forms that may have helped their bearers shelter their eggs and offspring (Hopp and Orsen 2004), attract mates with elaborate displays (Zhang et al. 2008), or improve traction as the flapping animal ran up an incline (Dial 2003). Somewhere along the line, some feathers evolved into structures that could support flight. 


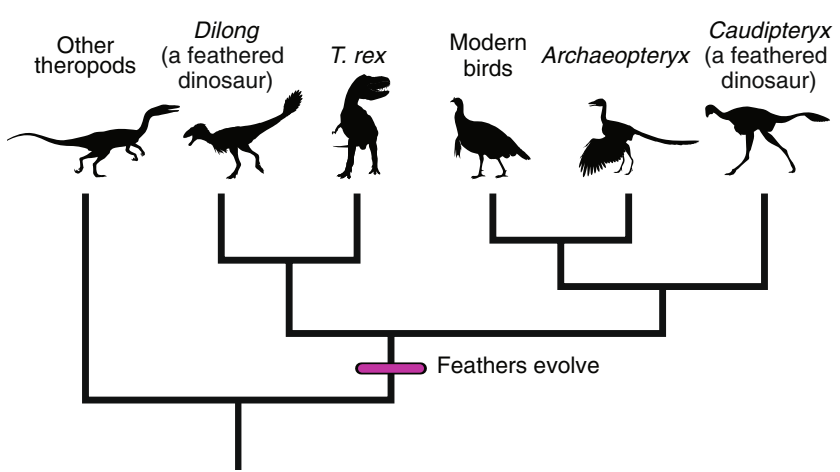

Fig. 1 Phylogeny of theropod dinosaurs showing select members and the origin of feathers

Hence, the existence of feathers was likely an adaptation for insulation (or something else) that has since been exapted for flight.

Exaptation is rampant in evolution. Any evolutionary process that involves co-opting a trait for a new function results in an exaptation. This means that all reasonably complex traits are likely to represent a layering of exaptations and adaptations. For an example, consider again the tail feather of a barn swallow. The existence of feathers is likely an adaptation for a function like regulating body temperature. Later, they became exapted for flight, and in tail feathers, they were exapted to play a role in aiding the bird's maneuverability as it flies (Matyjasiak et al. 2004). And still later, in the barn swallow's ancestors, that basic tail feather structure was exapted again for attracting the opposite sex. However, the current length of those tail feathers would be considered an adaptation for attracting the opposite sex. If we look at a feather and consider only its current adaptive value, we miss half the story.

\section{The Origin of a Concept}

The word exaptation was first proposed by Stephen Gould and Elisabeth Vrba (1982), but the idea itself is an old one dating back to the origins of evolutionary theory. Gould and Vrba point out that Darwin described examples of the concept in On the Origin of Species (1859). Darwin noted that mammals are born with unfused skull bones, which is especially important for human babies as it allows their heads to fit through the birth canal. Tempting as it is to herald this as a key adaptation for the birth of big-brained babies, Darwin recognized that it was not. He reasoned that since birds, lizards, and other vertebrates that hatch out of eggs have similarly unfused skull bones when they are born, this trait must have evolved long before any mammal needed to squeeze through a birth canal. These unfused skull bones probably first arose as a byproduct of other evolutionary forces reshaping the skeleton and have since come in handy for the birthing process of mammals. In Gould and Vrba's parlance, this would make the unfused skull bones of human babies an exaptation for fitting through the birth canal.

\section{The Importance of Exaptation}

If even Darwin used the concept of exaptation without having a specific term for it, one might wonder if we really need to bother with the extra vocabulary word. In fact, there are several reasons that the concept deserves a name of its own.

First, the word exaptation handily replaces a misleading and baggage-laden evolutionary concept, preadaptation. Prior to Gould and Vrba's 1982 paper, many biologists had referred to traits that evolved in one context before they were coopted for another function as preadaptations. For example, early thermo-regulating feathers would have been considered preadaptations for flight. This term is problematic because it smacks of anticipation - as though evolution had somehow planned those early feathers as the first step in the evolution of bird flight and that, once they evolved, their transformation into flight feathers was inevitable. But, of course, this is not how evolution works. Evolution has no intent or ability to think ahead. Natural selection is a mechanistic process that works with the available variation in a population and retains traits that are correlated with higher reproduction in the current circumstances. Evolution has no mechanism for working out what sorts of traits would be handy in the upcoming millennia.

Second, using the word exaptation emphasizes that many traits of organisms are not perfectly suited to their current function. When we say that a trait was exapted, we are being explicit about the fact that the trait first evolved in another context - and that this context may have been important in shaping its current state. Feathers may not be the perfect design for supporting flight partly because they did not first evolve to serve that function; the sutures in a human baby's skull may not be perfectly arranged to facilitate birth partly because they did not arise to serve that function. Terming these features exaptations reminds us that their current and future evolution may be constrained by their evolutionary history. Evolution rarely works from a blank slate.

Finally, by focusing attention on the contexts in which traits first evolved, the term exaptation encourages us to ask deeper questions about evolution. It is interesting, for example, to know that birds have hollow bones and that this helps them fly-but is this an adaptation or an exaptation for flight? Finding out would mean delving into birds' evolutionary history. There, we have discovered that birds' dinosaur ancestors - and even their massive dinosaur relatives like the 50 ton Sauroposeidon (Wedel and Cifelli 
2005) - had airspaces in their bones (Wedel 2006). These airspaces evolved long before bird flight did (Fig. 2). Why and how did they evolve? These intriguing questions would be easy to ignore if one focused exclusively on the current utility of hollow bones in birds.

\section{Examples of Exaptation}

Once you know to look for them, exaptations are everywhere. In this issue, Ian Tattersall applies the concept to the human capacity for symbolic thinking. He argues that the brain structures responsible for this capability evolved long before humans used language or other forms of symbolic cognition - making our current ability to think in symbols (e.g., words) an exaptation for the myriad of tasks to which we now apply this capacity - whether that is remembering the grocery list or building social bonds.

Exaptations come in many flavors - from an abstract ability, as proposed by Tattersall, to a physical structure (e.g., a flight feather). Here are a few examples of exaptations at different biological "levels":

- Protein-coding gene: animals have specialized proteins, called crystallins, in the lenses of their eyes that help refract light and allow them to see in focus. However, crystallins did not evolve de novo for this job. In fact, one of the crystallins important for our own sight (alpha crystallin) seems to have evolved from an ancient protein that, among other functions, helped protect cells from heat stress (see True and Carroll 2002 for a review of this example). Alpha crystallin is an exaptation for vertebrate vision.

- Gene regulation: the eyespots (the bold, bull's-eye patterns) on the wings of many butterflies likely help protect them from predators. As the butterfly metamorphoses, these spots develop partly in response to the action of a control gene called Distal-less. But Distalless did not evolve just to control coloration on the

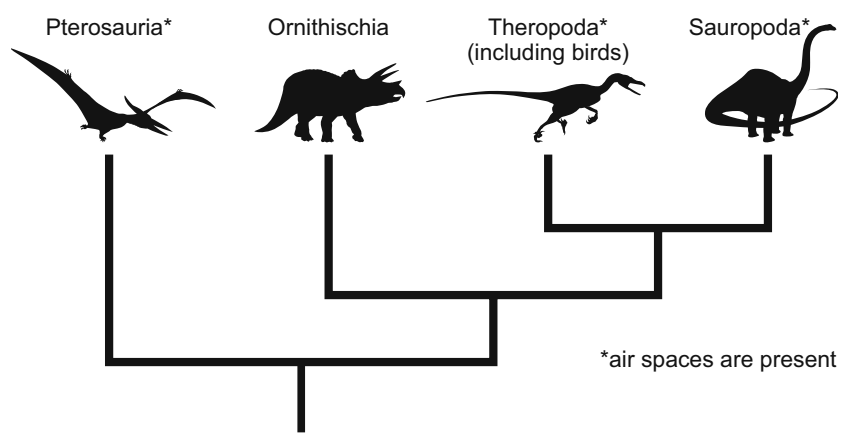

Fig. 2 Phylogeny of dinosaurs and relatives showing groups known to have had airspaces in their bones. The origin of this trait in the dinosaur lineage is identified wings of butterflies. In fact, the gene is found in animals ranging from fruit flies to humans and, in many of them, helps the developing organism build appendages (Robledo et al. 2002). Distal-less seems to have performed more ancient and basic jobs before being exapted to speckle the wings of butterflies (see True and Carroll 2002 for a review of this example).

- Complex physical structure: our legs (and those of other vertebrate land-dwellers) might seem like great adaptations for walking on land. Though they do serve this function well, their basic layout evolved when our ancestors were still splashing around in the water. For example, an early aquatic relative of our land-dwelling ancestors, Tiktaalik, probably used its sturdy forelimbs to prop itself up in shallow water (Shubin et al. 2006). The basic layout of our limbs is an exaptation for locomotion on land.

- Behavior: a flash flood is a signal to giant water bugs to head for higher ground, where they can avoid the dangers of a churning, violent river. The bugs seem to use heavy rainfall as a cue for them to make their escapes. However, this general response to rainfall likely evolved before water bugs ever invaded flashflood-prone desert streams and originally cued them to head for their seasonal breeding areas. In the groups that wound up living in regions with flash-flooding, this basic behavioral response was exapted for flash flood escape (Lytle and Smith 2004).

\section{Conclusion}

Exaptation is an important concept in helping us discuss and think about the evolution of the diversity of life. That is not to say that adaptations are not important. They are. We would all be pretty lousy at making a living if none of our traits were adapted for their current functions. The point is to recognize that adaptations are most frequently layered on top of exaptations - that all aspects of the living world, from the spots on a butterfly's wing to the human brain, are influenced not just by what works today but by the twists and turns of their unique evolutionary histories.

\section{Give Me an Example of That}

Want more examples of exaptations? Check these out:

- Quick bites and quirky adaptations. The fastest jaws in the world belong not to the great white shark or the lion but to the tiny trap-jaw ant, which can snap its jaws together at a remarkable 145 miles per hour! These jaws 
are useful in attacking predators, but they have also been exapted for a second function: escape. Some of these ants snap their powerful jaws against the ground when threatened to fling themselves up and away from danger. Read it at: http://evolution.berkeley.edu/evolibrary/news/ 061001 trapjaw

- Why the eye? Animal eyes are amazingly diverse in both their structures and evolutionary histories. They have evolved independently many times on the animal family tree. Remarkably, all these different eyes seem to be built by some of the same genes, for example the Pax6 gene. This module reviews eye evolution and delves into Pax6's evolutionary history to see how it likely functioned in the earliest animals. Read it at: http://evolution.berkeley.edu/evolibrary/ article/eyes_01

\section{Branch Out}

In this article, we have focused on exaptations, features that perform a function but that were not produced by selection for their current use. To learn more about their counterparts, adaptations, check out these resources from Understanding Evolution:

- How can a trait be identified as an adaptation? http:// evolution.berkeley.edu/evolibrary/article/qualifying_01

- If it is not an adaptation, what is it? http://evolution. berkeley.edu/evolibrary/article/misconcep_07

\section{Dig Deeper}

To learn more about the exaptations that four-legged vertebrates have for land-living and how these first evolved in our aquatic ancestors, visit this resource:

- What has the head of a crocodile and the gills of a fish? This news brief from Understanding Evolution discusses the evolutionary implications (and misinterpretations!) of the Tiktaalik fossil find. http://evolution. berkeley.edu/evolibrary/news/060501_tiktaalik

To learn more about the evolution of hollow bones in dinosaurs, visit this resource:

- Hunting the inflatable dinosaur. This short article from the UC Museum of Paleontology, on paleontologist Matt Wedel, discusses the early evolution of airspaces in dinosaur bones and what this can tell us about other parts of dinosaur anatomy that do not fossilize well. http://www.ucmp.berkeley.edu/science/ profiles/wedel_0609.php

\section{In the Classroom}

Though the topic of exaptation is most appropriate for high school and more advanced students, you can build the foundations to understand this concept early. Middle school students can begin to understand that the future evolution of organisms is constrained by their evolutionary history. The following lessons deal with the concept of evolutionary constraints for this age group:

- The arthropod story. This web activity for grades $6-12$ delves into the amazing world of the arthropods and examines their success and their evolutionary constraints. http://evolution.berkeley.edu/evolibrary/article/ arthropodstory

- Mantis shrimp shoulder their evolutionary baggage and bluff. This article for grades 6-12 explains that, like all organisms, mantis shrimp carry baggage from their evolutionary history. This baggage has coaxed them into a deadly bluffing game. http://evolution.berkeley. edu/evolibrary/article/mantisshrimp_01

High school and college students should be ready to take on the topic of exaptation and see how the concept applies to morphology, behaviors, and even genes. For this age group, consider the following resources:

- The evolution of flight in birds. This interactive module for grades 9-12 examines evidence from the fossil record, behavior, biomechanics, and cladistic analysis to interpret the sequence of events that led to flight in the dinosaur lineage. http://www.ucmp.berkeley.edu/education/ explorations/reslab/flight/main.htm

- From butterflies to humans. In lecture four of a series from the Howard Hughes Biointeractive website, evolutionary biologist Sean Carroll uses the developmental genetics of insects to explain how old genes can learn new tricks and how this can help us understand human evolution. http:// www.hhmi.org/biointeractive/evolution/lectures.html

Acknowledgements The author wishes to thank Judy Scotchmoor and Kevin Padian for helpful comments on earlier drafts, as well as David Smith for help developing images.

Open Access This article is distributed under the terms of the Creative Commons Attribution Noncommercial License which permits any noncommercial use, distribution, and reproduction in any medium, provided the original author(s) and source are credited.

\section{References}

Darwin C. On the origin of species. London: Murray; 1859.

Dial KP. Wing-assisted incline running and the evolution of flight. Science. 2003;299:402-4. 
Ewart JC. Nestling feathers of the mallard with observations on the composition, origin, and history of feathers. Proc Zool Soc. 1921;391:609-53.

Gould SJ, Vrba ES. Exaptation - a missing term in the science of form. Paleobiol. 1982;8:4-15.

Hopp TP, Orsen MJ. Dinosaur brooding behavior and the origin of flight feathers. In: Currie PJ, Koppelhus EB, Shugar MA, Wright JL, editors. Feathered dinosaurs. Bloomington: Indiana University Press; 2004. p. 234-50.

Janzen DH. Coevolution of mutualism between ants and acacias in Central America. Evolution. 1966;20:249-75.

Leisman G, Cohn DH, Nealson KH. Bacterial origin of luminescence in marine animals. Science. 1980;208:1271-3.

Lytle DA, Smith RL. Exaptation and flash flood escape in the giant water bugs. J Insect Beh. 2004;17:169-78.

Matyjasiak P, Matyjasiak J, De Lope F, Møller AP. Vane emargination of outer tail feathers improves flight maneuverability in streamerless hirundines, Hirundinidae. Proc R Soc Lond B. 2004;271:1831-8.

Møller AP, Barbosa A, Cuervo J, de Lope F, Merino S, Saino N. Sexual selection and tail streamers in the barn swallow. Proc $\mathrm{R}$ Soc Lond B. 1998;265:409-14.
Norrell MA, Xu X. Feathered dinosaurs. Ann Rev Earth Plan Sci. 2005;33:277-99.

Robledo RF, Rajan L, Li X, Lufkin T. The Dlx5 and Dlx6 homeobox genes are essential for craniofacial, axial, and appendicular skeletal development. Genes Dev. 2002;16:1089-101.

Shubin NH, Daeschler EB, Jenkins FA Jr. The pectoral fin of Tiktaalik roseae and the origin of the tetrapod limb. Nature. 2006;440:764-71.

Stetter KO. Extremophiles and their adaptation to hot environments. FEBS Lett. 1999;452:22-5.

Tattersall I. Becoming modern Homo sapiens. Evol Educ Outreach 2009;2, doi:10.1007/s12052-009-0164-x.

True JR, Carroll SB. Gene co-option in physiological and morphological evolution. Annu Rev Cell Dev Biol. 2002;18:53-80.

Wedel MJ. Origin of postcranial skeletal pneumaticity in dinosaurs. Int Zool. 2006;2:80-5.

Wedel MJ, Cifelli RL. Sauroposeidon: Oklahoma's native giant. Oklahoma Geol Notes. 2005;65:40-57.

Zhang F, Zhou Z, Xu X, Wang X, Sullican C. A bizarre Jurassic maniraptoran from China with elongate ribbon-like feathers. Nature. 2008;455:1105-8. 